\title{
A Review Paper \\ RECENT ADVANCES IN ASSESSMENT OF MARINE LIPID OXIDATION BY \\ USING FLUORESCENCE
}

Santiago P. Aubourg

Instituto de Investigaciones Marinas (CSIC)

c/ E. Cabello, 6

36208-VIGO (Spain)

Phone: + 34-986-231930

Fax: + 34-986-292762

E-mail: saubourg@iim.csic.es

Running Title: Lipid oxidation assessment by fluorescence detection 


\begin{abstract}
Lipid changes during food processing are important because of their impact on the final product quality. Lipid damage detection is limited because of the ability of lipid oxidation products (i. e. hydroperoxides and carbonyl compounds) to produce interaction compounds by reacting with nucleophilic food constituents. Fluorescence quantification at a single excitation/emission maximum of these interaction compounds has been employed in a qualitative way as a complementary tool for food quality assessment. The present work reviews recent research where simultaneous detection at different excitation/emission maxima was employed to assess lipid oxidation and quality changes during fish processing. Thus, a fluorescence shift towards a higher wavelength maxima was detected as a result of lipid damage; the shift was calculated as the ratio $(\delta F)$ between two of the maxima tested $(393 / 463 \mathrm{~nm}$ and $327 / 415 \mathrm{~nm})$ and was investigated along different fish processes (freezing and frozen storage, refrigerated storage, cooking and canning) and in complementary model systems where the influence of different factors (time and temperature of processing, amine and aldehyde composition and content, formaldehyde presence and $\mathrm{pH}$ value of the medium) was checked. Determination of the $\delta \mathrm{F}$ value provided better results for quality changes assessment in fish products than most of the lipid quality indices, in addition to be rapid and sensitive.
\end{abstract}

Key Words: Fluorescence, food, interaction compounds, lipid damages, marine species, processing, quality. 
From the moment a biological species is killed, captured or harvested until it is consumed as a food, its original properties may be modified as a result of changes of chemical constituents undergone during the specific conditions of processing. Rancidity of fats and oils has been shown to play a very important role in the degradation processes that take place in foods $(1,2)$. During processing and storage enzymatic and non enzymatic lipid oxidation occur. A close relationship has been found between lipid damage and quality of the final product $(3,4)$. Lipid degradation is especially important in foods coming from biological species where a high unsaturated lipid composition is present, such as in marine species that contain a high content on polyunsaturated fatty acids (PUFA) $(5,6)$.

PUFA damages can greatly lead to primary and secondary lipid oxidation products which can react with amino constituents (proteins, peptides, free amino acids and phospholipids) to produce interaction compounds (7-9). As a result, browning, flavor changes and loss of essential nutrients occur (10-12).

Many methods have been used to measure primary (peroxides) and secondary (carbonyl compounds) oxidation products to determine deterioration. There are, however, difficulties associated with common methods, especially where much damage has occurred, as in the case of biological species supporting a great fat content and PUFA proportion when processed by heat treatments. Oxidation products are unstable and tend to react with food constituents, so their detection may not be a valid tool for quality assessment in all cases $(13,14)$. As a result, the detection of interaction compounds has recently attracted attention in assessing food quality. Fluorescence analysis has been widely explored, in this regard. The present work reviews recent research employing fluorescence detection of interaction compounds as a quantitative 
tool for quality assessment. The formation, significance and detection of the interaction compounds and previous use of fluorescence for food quality assessment are considered.

\section{INTERACTION COMPOUNDS: FORMATION AND SIGNIFICANCE}

The electrophilic character of most lipid oxidation compounds leads them to interact with food constituents possessing nucleophilic functions. The interactions are very important secondary reactions of oxidized lipids, particularly in protein-rich foodstuffs such as marine sources, which have a high proportion of essential and reactive amino acids such as lysine and methionine (15).

Chemical bonds of interaction compounds produced in foods may be of three types (7): physical, ionic and covalent. The physical bonds (e.g. hydrogen bonds between polar groups and physical forces between hydrophobic groups) are usually weak, and therefore easily split by the action of solvents like methanol. However, if several such bonds are present in the molecule, their combined strength may become sufficiently great to resist the polar solvents. The hydrogen bonds are formed almost immediately, even at room temperature. The formation of these bonds is manifested by a decrease in solubility of the lipid fraction in organic nonpolar solvents. The ionic bonds are also relatively weak, and can easily be split by polar solvents, and therefore, are less important in products of oxidized lipids with proteins.

Covalent bonds are relatively strong and resistant to the action of solvents. Their formation proceeds slowly, i.e. within several weeks at room temperature, but is accelerated to a few days by heating. The structure of covalent interaction compounds 
can vary, depending on the lipid and protein groups interacting (Figure 1). Biological amines may react with lipid peroxides (Reaction 1) and aldehydes (Reaction 2). In both cases, an adduct compound (Schiff base) is produced. If this reaction is repeated several times, the conjugated double bond system is enlarged and the color intensity of the molecule formed is increased (Reaction 3) $(1,7,8)$.

As in the case of Maillard reactions between sugars and amino acids, the interactions between oxidized lipids and proteins affect the nutrition and sensory values of food. Several effects on nutritional value can be noted $(7,12)$ : a) Decrease of biological value of protein (blocking of free $\varepsilon$-amino groups of L-lysine by reacting with alkanals; oxidation of sulphide group of L-methionine; changes in other amino acids: cysteine, cystine, triptophane, histidine and tyrosine); b) Changes of digestibility (decreased rate of lipolysis by lipases; decreased rate and extent of proteolysis by digestive enzymes); and c) Deactivation of toxic substances produced by lipid autoxidation (lipid hydroperoxides and lower aldehydes).

Formation of interaction compounds can also influence the sensory value of food in various ways (7): flavor, color and texture. Some flavor substances produced by lipid oxidation, e.g. lower aldehydes, may be bound to protein on storage or heating. The browning reaction is the most conspicuous change of sensory properties due to these interactions. The presence of polyenoic fatty acids and free amine groups of protein seems indispensable for the formation of brown products. A linear correlation has been detected among browning and the extent of aldehyde-protein interaction and the formation of nonextractable lipid-protein products (7). Changes of texture are mostly due to crosslinking of peptide chains by reaction with lipid oxidation products, e.g. aldehydes. 
First attempts to study the formation of interaction compounds were carried out to assess lipid oxidation in living tissues $(16,17)$. For a long time, microscopists studied the so called "age-pigments" or "lipofuscin" resulting from a degenerative process in cells such as aging, environmental stress and vitamin E deficiency $(18,19)$. As a result, peroxidation of membrane phospholipids disrupts membrane structure and function so that changes may be manifested by decreased membrane fluidity, altered membraneprotein activity and the failure of the membrane to act as a semipermeable barrier (20).

Thus, solution fluorescence spectrophotometry was used as a method to measure the extent of peroxidation in living material. Tappel and co-workers (16) studied the fluorescent chromophore $\mathrm{R}-\mathrm{N}=\mathrm{CH}-\mathrm{CH}=\mathrm{CH}-\mathrm{NH}-\mathrm{R}$ which they believed to be responsible for the spectral properties observed in lipofuscin, according to a malondialdehyde (MDA) interaction with $-\mathrm{NH}_{2}$ groups from biological molecules, to produce the mentioned Schiff base. Later, Nair and co-workers $(21,22)$ proved the difficulty in obtaining the proposed fluorophore starting from pure MDA in the presence of amino compounds, while Kikugawa and co-workers (17) isolated 1,4-dihydropyridines as a new type of fluorescent compound produced by the reaction of MDA and amino compounds.

As a result, evidence on the importance of other carbonyl compounds in the formation of lipofuscin type fluorescent products surfaced. Tsuchida et al. (23) suggested that the water soluble fluorescent substances in the protein fraction of mouse and human sera might not be conjugated Schiff bases formed from protein and MDA but be due to some other stable compounds. It was suggested $(24,25)$ that fluorescent chromolipids formed by lipid peroxidation are derived from 4-hydroxynonenal or similar reactive aldehydes, since the formation of high molecular weight proteins more or less parallels the formation of chromolipids, but not the formation of MDA. 


\section{DETECTION OF INTERACTION COMPOUNDS}

Different analytical procedures have been employed in order to follow the interaction between oxidized lipids and proteins. Remaining $-\mathrm{SH}$ and $-\mathrm{NH}_{2}$ groups in different kinds of protein extracts have been assessed by means of specific reactions; techniques such as sodium dodecyl sulfate-electrophoresis, permeation chromatography, high performance liquid chromatography (HPLC), ultraviolet-absorption and brown color development have been employed (26-28). Capillary zone electrophoresis (29) proved useful for separating small amounts of typical complex mixtures of Maillard reaction products arising from mixtures including free amino acids and aldehydic sugars; separation and partial characterization were carried out. The advantages of capillary electrophoresis in separating melanoidin compounds were assessed by comparison with reversed HPLC (30).

Once fluorescent compounds were successfully used as an analytical method for quantifying peroxidation damage to biological tissues, this technique was widely employed in order to assess lipid oxidation in foods. Recently, this kind of detection has become the most employed method for analyzing interaction compounds during food processing. In the next section, some examples concerning this application will be reviewed.

Fluorescence is a rapid and sensitive method for characterizing molecular environments and events. Its theory and methodology have been extensively employed for studies of molecular structure and function in the disciplines of both chemistry and biochemistry (20). Fluorescence spectrophotometry is characterized by two distinct spectra: excitation and emission. Emission occurs at a longer wavelength than the 
incident light (excitation) because the energy of the emitted radiation differs from that absorbed by an amount equal to the vibrational energy lost to the surroundings (31).

\section{LIPID OXIDATION ASSESSMENT IN FOODS BY FLUORESCENCE DETECTION}

Fluorescence research has been conducted on different kinds of foods and processes during the last three decades. Frequently, the fluorescence spectrum is studied and then a single excitation/emission maximum is chosen to be quantified and employed for lipid oxidation assessment; however, in most applications, fluorescence is used as a qualitative tool and complementary of other more developed techniques. Quantitative determinations and correlations with accepted traditional quality indices have been very scarce in fluorescence research. The next two subsections are divided into marine and non-marine sources because of differences in the PUFA content and the impact on the fluorescence development.

Some controversy exists in the literature regarding the kind of extract or material that should be analyzed by fluorometry. Fluorescence determinations of treated samples have been demonstrated in organic extracts $(32,33)$, aqueous extracts $(19,34)$, both types of extracts $(35,36)$ and solid sample spectrofluorometry (37).

Organic extracts have been widely employed for studying fluorescence development during damage of living tissues. Membrane lipids (i. e. phospholipids) are involved and a water non-soluble fluorescent complex was reported to be formed, since phospholipids acted as amino donors $(16,38)$. However, if protein amino compounds are involved as amino donors, fluorescent substances formed would remain attached to the amino constituent $(39,40)$; in this case, fluorescent compounds could not be extracted with organic solvents, but rather with aqueous ones. Depending on the nature 
of the amino donor, the resulting Schiff base complex may have either polar or non polar properties.

\section{Non-marine foods}

Detection of fluorescent compounds extracted with an organic solvent mixture provided reproducible results reflecting well the progress of oxidation in milk (32) and frying oils (41). Comparison of absorption and intrinsic fluorescence of aromatic residues of proteins of soft wheat flour and gluten gave information on the interactions of lipids and proteins in these complex systems (42).

Fluorescence levels measured in the organic and aqueous layers arising from Folch lipid extraction were effective in assessing damage during chicken breast and leg meat processing(35). The initial levels of either MDA or fluorescent products in meat are of primary importance in determining the final MDA and fluorescence levels after processing. The extent of warmed-over flavor (WOF) formation in cooked beef was studied (43). Correlation of WOF with sensory evaluations in which a trained sensory panel evaluated WOF smell and WOF taste, showed that thiobarbituric acid reactive substances (TBARS) and fluorescence analysis of the organic extract of the muscle are suitable for monitoring the development of WOF in reheated cooked beef during storage. Spectrofluorometry technique was directly applied on solid food samples during freeze-drying of pork and egg yolk (44); fluorescence intensity showed a high positive correlation with the absorbed oxygen level; however, thiobarbituric acid index (TBA-i) and peroxide value (PV) were not suitably correlated with the absorbed oxygen in all cases.

Fluorescence also has been used for food authenticity identification. A multispectral fluorescence imaging system was tested to distinguish several vegetable food products (maize, pea, soy bean and wheat). Application of stepwise discriminant 
analysis showed that identification of the four products was possible with fluorescence (45). Future work should include the study of mixtures of food products and the identification of contaminants in grain and seed samples. Fluorescence spectra of apple juice were evaluated to relate picking date of the apple with traditional harvest indices (46). Apples with different picking dates could be correctly classified by their fluorescence spectra. However, the authors concluded that a model based on a broader set of parameters should be tested to overcome the problem of large interapple variation.

New possibilities for analytical characterization of virgin olive oil, refined olive oil and hask oil were obtained by studying their fluorescence spectra (47). Four types of edible oils were characterized by their three dimensional (excitation and emission wavelength and emission intensity fluorescence spectra) fluorescence topograms; all oils displayed characteristic topograms, whose curve patterns were distinctly different (48). In both experiments $(47,48)$, complementary research should be carried out with more oil types and mixtures to create methods to use against fraud.

\section{Marine foods}

Changes were observed in the muscle fluorescence of many species of fish during storage in the frozen state; it was suggested that careful visual examination of fish muscle fluorescence, before and after thawing, could be useful in the assessment of cold storage history (49). Two fluorescent emissions developed in fish muscle during frozen storage were investigated and related to fish quality, although quantitative results were not obtained (50); carbonyl compounds arising from lipid oxidation compounds and formaldehyde produced by degradation of trimethylamine oxide were thought to be involved in both fluorescences. 
Determination of interaction compounds such as polymers, fluorescent material in the lipid extract and browning matter was found to be reliable in evaluating oxidative deterioration during sardine freeze-drying (51). Rancidity scores and several chemical assessments of lipid degradation (PV, conjugated dienes content, browning, fluorescence and amino acid composition changes) were made on dried-salted sardines stored at three temperatures $\left(5^{\circ} \mathrm{C}, 20^{\circ} \mathrm{C}\right.$ and $\left.30^{\circ} \mathrm{C}\right)$ for 24 weeks; the presence of fluorescent products measured in the lipid fraction, showed a significant correlation with sensory scores (52). Sun dried or salted fatty fish showed highly positive correlations between the odor of the stored products and the fluorescent pigment production measured in the lipid fraction $(33,36)$. Determination of extractable fluorescence (aqueous and organic phases resulting from lipid extraction) and soluble brown color were found to be relevant indicators of the lipid oxidation in salted sundried fish (36).

Fish meats were measured directly before and after lipid extraction by solid sample spectrofluorometry (37) for the quantitative assessment of oxidative deterioration in freeze-dried fish. For it, two fluorescences (370/460 nm and 450/500 nm) were tested. PV, TBA-i and fluorescence intensities of organic solvent extracts did not correlate well with the extent of lipid oxidation determined by oxygen absorption. However, fluorescence measured at 450/500 nm in defatted fish muscle provided a high correlation with oxygen absorption. It was concluded, that such solid sample fluorescence detection could be valuable to quantify the oxidative deterioration; in this sense, more experiments concerning a wider range of fish material and processing conditions are necessary. 


\section{QUALITY ASSESSMENT BY FLUORESENCE SHIFT DETECTION DURING FISH PROCESSING}

During the last ten years, experiments carried out in our research group have focused on the formation of interaction compounds. With this purpose, simultaneous fluorescence detection at several excitation/emission maxima during fish species processing was employed. The research was aimed in employing fluorescence detection as a quantitative tool for the quality assessment during food processing.

In our first attempts $(53,54)$, it was observed that fluorescent compounds formed during the first stages of the reaction or processing gave rise to other fluorescent compounds showing higher wavelength maxima as a result of increased food damage. This observed batochromic shift agrees with the general theory of progressive formation of Schiff bases and other interaction compounds with increasing molecular weights and unsaturated bond number (7-9) (Figure 1). From these initial experiments, it was observed that this fluorescence shift could be assessed by calculating the ratio $(\delta \mathrm{F})$ between two of the excitation/emission maxima tested (393/463 nm and 327/415 nm).

The following research steps were focused on correlating this $\delta \mathrm{F}$ value with common fish quality indices along different fish processes. Since no previous information was available concerning the kinds of compounds that were measured at fluorescence maxima, both the aqueous and organic (lipid extract) phases resulting from the lipid extraction ( $\delta \mathrm{F}_{\mathrm{aq}}$ and $\delta \mathrm{F}_{\text {or }}$, respectively) were analyzed for all experiments.

\section{Freezing and frozen storage}

Sardine (Sardina pilchardus) fish was kept frozen $\left(-18^{\circ} \mathrm{C}\right.$ and $\left.-10^{\circ} \mathrm{C}\right)$ up to two years (55). Fluorescence results $\left(\delta \mathrm{F}_{\mathrm{aq}}\right.$ and $\left.\delta \mathrm{F}_{\text {or }}\right)$ were compared to common quality 
indices [total volatile base-nitrogen (TVB-N), conjugated dienes (CD), TBA-i and free fatty acids (FFA)].

At $-18^{\circ} \mathrm{C}$, the $\delta \mathrm{F}_{\mathrm{aq}}$ value showed significant $(\mathrm{p}<0.01)$ correlations with storage time $(r=0.80)$, TBA-i $(r=0.92)$ and FFA content $(r=0.83)$. These two classical indices (TBA-i and FFA) have been recognized as useful in this kind of storage, since enzymatic lipid damage has shown to be a decisive degradation pathway $(56,57)$. Indeed, lipid hydrolysis has been reported to facilitate further oxidation $(58,59)$. Principal component analysis (Figure 2) showed that the $\delta \mathrm{F}_{\mathrm{aq}}$ was grouped together with the storage time, FFA and TBA-i at high loading in the Factor 1 axis, whereas their loading values for Factor 2 were low. The $\delta F_{\text {or }}$ detection, however, did not afford satisfactory quality assessment.

The highest temperature $\left(-10^{\circ} \mathrm{C}\right)$ studied in this experiment (55) produced more lipid damage. The best fluorescence results were obtained, again, in the case of the $\delta \mathrm{F}_{\mathrm{aq}}$ value, showing a significant $(\mathrm{p}<0.01)$ correlation with the TBA-i $(r=0.81)$ and also significant $(\mathrm{p}<0.05)$ correlation with the storage time $(\mathrm{r}=0.72)$, FFA $(\mathrm{r}=0.59)$ and TVB-N ( $\mathrm{r}=0.60)$. A principal component analysis (Figure 3 ) showed that $\delta \mathrm{F}_{\mathrm{aq}}$ was grouped with the same indices as for $-18^{\circ} \mathrm{C}$ (storage time, FFA and TBA-i) and also with TVB-N index, according to some microbiological activity development $(60,61)$; all these parameters showed a high loading in the Factor 1 axis.

\section{Refrigerated storage}

Sardine fish was kept refrigerated $\left(0^{\circ} \mathrm{C}\right.$ on ice) up to 16 days (62). Fish muscle alterations were checked by measuring the fluorescence shift $\left(\delta \mathrm{F}_{\mathrm{aq}}\right.$ and $\left.\delta \mathrm{F}_{\mathrm{or}}\right)$ value and compared again with common quality indices (TVB-N, FFA, CD and TBA-i). The TVB-N detection, was emphasized because it is an important index for microbiological 
activity during the refrigerated storage $(60,61)$. In our results (62), a high and significant $\left(\mathrm{p}^{<0.05)}\right.$ correlation was found (Table $\left.1 \mathrm{~A}\right)$ for the $\delta \mathrm{F}_{\mathrm{aq}}$ value with the TVB$\mathrm{N}(\mathrm{r}=0.93)$ and the refrigerated storage time $(\mathrm{r}=0.94)$. Among the lipid indices, the $\delta \mathrm{F}_{\mathrm{aq}}$ value showed the best correlation with refrigerated storage time, even better than the TVB-N. Regarding frozen storage, the $\delta \mathrm{F}_{\text {or }}$ value did not provide satisfactory results for assessing quality changes and for correlating with other quality indices.

A complementary study was carried out by holding sardines at $15^{\circ} \mathrm{C}$ for 8 days (62). Common indices and fluorescence analysis ( $\delta \mathrm{F}_{\mathrm{aq}}$ and $\delta \mathrm{F}_{\text {or }}$ values) showed more damage than during refrigerated storage. Correlation results between parameters can be seen in Table $1 \mathrm{~B}$. The $\delta \mathrm{F}_{\text {or }}$ is not included, since no satisfactory results were obtained. The storage time showed significant $(\mathrm{p}<0.05)$ correlation values with all the indices, especially with the TVB-N, FFA and $\delta \mathrm{F}_{\mathrm{aq}}$ value. At the same time, the $\delta \mathrm{F}_{\mathrm{aq}}$ value also provided significant $(\mathrm{p}<0.05)$ correlations with all the parameters studied.

Changes during refrigerated $\left(0^{\circ} \mathrm{C}\right.$ in ice) storage of a lean fish species (Micromesistius poutassou) were studied (63). Again, different kinds of lipid damage indices (PV; CD; TBA-i; FFA; polyene index, $\mathrm{PI} ; \delta \mathrm{F}_{\mathrm{aq}}$ and $\delta \mathrm{F}_{\text {or }}$ ) were investigated and compared to TVB-N content. Similarly to previous results regarding a fatty fish species (sardine), fluorescence detection of interaction compounds formed in the aqueous medium $\left(\delta \mathrm{F}_{\mathrm{aq}}\right.$ value) showed the best correlation with the time of storage (nonlinear relationship; Figure 4) and the TVB-N evolution (linear relationship; Figure 5) and provided the highest independent contribution to time prediction during refrigerated storage.

\section{Cooking}


Two tuna species (big eye, Thunnus obesus; bluefin, Thunnus thynnus) were steam cooked $\left(102-103^{\circ} \mathrm{C}\right.$, to a final backbone temperature of $\left.65^{\circ} \mathrm{C}\right)(64)$. The lipid damage was investigated using conventional (FFA, CD, carbonyls and browning) and fluorescence ( $\delta \mathrm{F}_{\mathrm{aq}}$ and $\delta \mathrm{F}_{\text {or }}$ values) detection methods, and the results were compared. As a consequence of the thermal treatment, $\delta F_{\text {or }}$ value increased (cooked/raw ratios $>1$, Table 2), according to changes undergone by other conventional indices of lipid damage (i. e. carbonyls, browning and FFA). Different individual fish were studied in both tuna fishes (BE1-BE5 and BF1-BF4, Table 2); as a result, the $\delta F_{\text {or }}$ value showed a lower variation coefficient than did the remaining conventional methods, showing that the fluorescence detection was less dependent on the individual fish sample studied. Similar conclusions were obtained by analyzing the $\delta \mathrm{F}_{\text {aq }}$ value.

\section{Canning}

Thermal treatment during sterilization has been reported to produce many changes in fish muscle; however, many of the problems encountered with poor quality canned fish can be related to the quality of the raw material, which continuously changes during storage (2). Refrigerated and frozen storages are the most utilized methods in canneries for preserving fish prior to canning. Accordingly, refrigerated and frozen sardines were employed by our group to determine the influence of the storage time of fish (raw material quality) over the quality of the final canned product measured by the $\delta \mathrm{F}$ value and traditional indices (65). Refrigerated $\left(0^{\circ} \mathrm{C}\right.$, on ice) sardines were canned in brine (Table 3), while frozen $\left(-18^{\circ} \mathrm{C}\right)$ sardines were canned in oil (Table 4); sterilization was carried out in a retort $\left(115^{\circ} \mathrm{C}, 45 \mathrm{~min}\right)$.

The common indices of lipid degradation (FFA, CD, TBA-i and PI) measured in canned sardines did not reflect quality changes according to the previous time of storage 
of the raw material (Tables 3 and 4). It could be argued that degradation products measured in such indices can either be distributed into different phases of the can (packing medium, exudate, fish muscle), be partly destroyed during the heat process or interact with other constituents so that their assessment was not an accurate measure of quality.

Fluorescence analysis of fish muscle extracts $\left(\delta \mathrm{F}_{\mathrm{aq}}\right.$ and $\delta \mathrm{F}_{\mathrm{or}}$; Tables 3 and 4$)$ afforded poor results for quality changes assessment. These results might be explained by the presence in the can of a packing liquid (brine or oil), which could act as an extraction medium of the solid phase. The analysis of the fluorescence ratio value, however, in both packing media (brine and oil; $\delta \mathrm{F}_{\mathrm{pm}}$ ) showed a satisfactory quadratic correlation ( $r=0.90$ in brine; $r=0.91$ in oil) with the time of storage of the raw material employed before canning. Therefore, quality differences in the final canned product could be assessed according to quality of raw material employed.

\section{FACTORS AFFECTING THE $\delta$ F VALUE}

Complementary research was carried out in our group to study the influence of different factors in the $\delta \mathrm{F}$ value. Fluorescence detection was checked in accurate model systems and results are shown in the following subsections.

\section{Time and temperature of processing}

In a first attempt (53), a model system mixture consisting of a lipid oxidation compound (acetaldehyde) and albacore (Thunnus alalunga) white muscle was studied. Several fluorescence maxima (327/415 nm, 393/463 nm and 479/516 nm) were detected 
and studied accordingly in the aqueous reaction medium and in the lipid extract of the mixture. A strong relationship between fluorescence formation in both media and time and temperature of reaction was evident. An augmentation in these parameters produced a significant shift of fluorescence formed to higher excitation/emission maxima wavelengths, leading to higher $\delta \mathrm{F}$ values in both phases.

In the previously mentioned experiments $(55,62,63)$, different times and temperatures during frozen and refrigerated storages were tested. A higher $\delta F$ value in the aqueous phase $\left(\delta \mathrm{F}_{\mathrm{aq}}\right)$ occurred when increasing the time and temperature of storage.

Four different sterilization conditions $\left(110^{\circ} \mathrm{C}, 120 \mathrm{~min} ; 130^{\circ} \mathrm{C}, 120 \mathrm{~min} ; 115^{\circ} \mathrm{C}\right.$, $60 \mathrm{~min} ; 130^{\circ} \mathrm{C}, 27 \mathrm{~min}$ ) were tested for albacore canning (54). Different fluorescence maxima (327/415 nm, 356/416 nm, 393/463 nm and 446/490 nm) were evaluated. A fluorescence shift to higher wavelength maxima measured in both the aqueous $\left(\delta \mathrm{F}_{\mathrm{aq}}\right)$ and organic $\left(\delta \mathrm{F}_{\mathrm{or}}\right)$ phases was observed as a result of processing. The strongest sterilization treatment $\left(130^{\circ} \mathrm{C}, 120 \mathrm{~min}\right)$ had the greatest lipid damage and $\delta \mathrm{F}$ value in both phases.

\section{Amine composition and content}

Different kinds of amines (different substitution degree and steric hindrance) were tested in model systems to quantify the $\delta \mathrm{F}$ value of the reaction medium (66). Primary (butylamine, iso-butylamine, sec-butylamine and tert-butylamine), secondary (dibutylamine) and tertiary (tributylamine) amines produced changes in the fluorescent properties of the systems during reaction at $30^{\circ} \mathrm{C}$ for 25 days with cod liver oil and glutaraldehyde. Greater $\delta \mathrm{F}$ values were associated with a lower degree of substitution (primary amines) and steric hindrance (butylamine and iso-butylamine) of the $-\mathrm{NH}_{2}$ 
group, caused by a higher nucleophilic ability for reacting with lipid oxidation compounds.

Influence of the chain length also was studied (66) in different primary amines (methylamine, ethylamine, propylamine, butylamine and octylamine) by reacting with cod liver oil at $30^{\circ} \mathrm{C}$ (Table 5). Greater $\delta \mathrm{F}$ values were obtained at the end of the reaction time as a result of increased chain length. Longer chain lengths may provide the amine molecule with a more lipid-type structure, so that interaction with lipid oxidation compounds would be facilitated (25).

Different amine (butylamine, dibutylamine and tributylamine) concentrations (0.2, 0.8, 4.0 and $20.0 \mathrm{mM}$ ) were tested by reacting with cod liver oil for 25 days at $30^{\circ} \mathrm{C}$ (66). In all cases, a higher $\delta \mathrm{F}$ value in the reaction medium was observed as the amine content increased, showing that the formation of fluorescent compounds depended not only on the presence of lipid oxidation compounds, but also on the amine content present in the biological matter.

\section{Aldehyde composition and content}

During the model system interaction between acetaldehyde and tuna muscle just mentioned (53), different aldehyde contents (0,1, 2 and $5 \%$, acetaldehyde/albacore muscle, w/w) were tested. A bigger fluorescence shift was produced according to the acetaldehyde content that was present in the reaction medium. This batochromic shift suggests a progressive formation of Schiff bases with increased molecular weights and unsaturated bonds number (7-9) (Figure 1).

The relative ability of different aldehydes (formaldehyde, acetaldehyde, propanal, hexanal, 2-hexenal and benzaldehyde) in producing fluorescent compounds related to the $\delta \mathrm{F}$ value was studied (67). Aldehydes were compared in model systems by 
reacting for 25 days at $30^{\circ} \mathrm{C}$ with n-propylamine and minced sardine white muscle as nucleophilic compound sources. A fluorescence development in the aqueous reaction medium was detected for all the aldehydes during the reaction time increased. Great differences, however, were observed among aldehydes, according to their chemical structure and reactivity. A sharp shift to a higher wavelength maxima was detected during storage for 2-hexenal and acetaldehyde because of a greater reactivity detected in reactions involving unsaturated and short carbonylic compounds (24, 25). Few changes in fluorescence formation were observed for formaldehyde and benzaldehyde.

\section{Formaldehyde presence and $\mathrm{pH}$ value}

During the frozen storage of gadoid fish species, formaldehyde (FA) is produced, along with dimethylamine, by enzymatic reduction of trimethylamine oxide. FA has been recognized as a highly reactive molecule leading to inter- and intramolecular linkages between protein chains. As a result, protein denaturation and quality loss in frozen fish have been associated with FA formation $(68,69)$.

In a recent work, the influence of FA on the $\delta \mathrm{F}$ value measured in the aqueous reaction medium was studied (70). A model system of fluorescence formation was set up, in which FA reacted at $30^{\circ} \mathrm{C}$ for 25 days with n-propylamine and minced fish muscle. The FA was less able to produce fluorescent compounds than common fish oxidation compounds, which were also tested (i. e. propanal and hexanal). Model systems consisting of FA and fatty fish (sardine) muscle, however, produced a higher $\delta \mathrm{F}$ value than did FA and lean fish (cod), because of greater lipid oxidation compound formation of the fatty fish system under the reaction conditions. Results obtained are summarized in Table 6. 
The effect of the $\mathrm{pH}$ value of the medium on the fluorescence development was evaluated (71). For this purpose, a model system consisting of minced hake (Merluccius merluccius) muscle in $0.1 \mathrm{M}$ phosphate buffer of different $\mathrm{pH}$ values (5.0, 6.0, 7.0 and 8.0) stored at $30^{\circ} \mathrm{C}$ for up to 30 days was studied. The presence/absence of FA in the reaction medium also was evaluated. In the absence of FA, no significant $(p<0.05)$ differences were obtained for the $\delta \mathrm{F}$ value measured in the aqueous reaction medium as $\mathrm{pH}$ changed. The presence of FA, however, in the same reaction mixture had a positive effect on the fluorescence shift development (Table 7), so that the following increasing $\delta$ F values were obtained: $\mathrm{pH} 5, \mathrm{pH} 6<\mathrm{pH} 7<\mathrm{pH}$. This result can be explained by analyzing the pKa values of the biological amine compounds involved (72). As long as the $\mathrm{pH}$ increases, the nucleophilic ability of $\mathrm{N}$-terminal groups of proteins and $\mathrm{R}$ terminal groups of basic amino acids (lysine, tyrosine and arginine) is increased, so that the formation of interaction compounds is favored.

\section{PROPOSED FUTURE RESEARCH}

The interesting results obtained for the $\delta \mathrm{F}$ value detection suggests several areas of further research: a) A better knowledge of the mechanism formation and identification of fluorescent compounds involved; b) Application of this detection method to a wide range of foods including non-marine biological species; c) Detection of the $\delta \mathrm{F}$ value in a wide range of food processes, including new and traditional ones, where lipid oxidation plays an important role (under-vacuum cooking, lipid-derived coatings, modified atmospheres, addition of natural and synthetic antioxidants, drying and salting). 


\section{ACKNOWLEDGMENTS}

The author acknowledges Dr. Isabel Medina and Dr. Carmen G. Sotelo for participation in the elaboration of results, and Mr. Oscar Bellón, Mr. Marcos Trigo and Mrs. Montserrat Martínez for technical assistance. Financial support was obtained from Comisión Interministerial de Ciencia y Tecnología (CICYT) (Spain) (Project ALI 900773; 1991-93), Xunta de Galicia (Spain) (Project XUGA 402 01B93) (1994-95) and the European Community (Project FAIR-CT95-1111) (1996-99). 


\section{REFERENCES}

1. Cheftel, J. C., and H. Cheftel, Oxidación de lípidos, in Introducción a la Biología y Tecnología de Alimentos, Editorial Acribia, Zaragoza (Spain), 1976, pp. 265290.

2. Pigott, G., and B. Tucker, Science opens new horizons for marine lipids in human nutrition, Food Rev. Int. 3: 105-138 (1987).

3. Hsieh, R., and J. Kinsella, Oxidation of polyunsaturated fatty acids: mechanisms, products, and inhibition with emphasis on fish, Adv. Food Res. Nutr. Res. 33: 233-341 (1989).

4. German B., H. Zhang, and R. Berger, Role of lipoxygenases in lipid oxidation in foods, in Lipid oxidation in food, edited by A. St. Angelo, American Chemical Society, Washington, DC, 1992, pp. 74-92.

5. Kinsella, J., Dietary fats and cardiovascular disease, in Seafoods and Fish Oils in Human Health and Disease, edited by R. Lees, and M. Karel, Marcel Dekker, Inc., New York and Basel, 1987, pp. 1-23.

6. Ackman, R. G. Fatty acids, in Marine biogenic lipids, fats and oils, edited by R. Ackman, CRC Press, Boca Raton, Florida (USA), 1989, vol. 1, pp. 103-137.

7. Pokorný, J., Interactions of oxidized lipids with proteins, Riv. Ital. Sostanze Grasse 54: 389-393 (1977).

8. Gardner, H. W., Lipid hydroperoxide reactivity with proteins and amino acids: A review. J. Agric. Food Chem. 27: 220-229 (1979).

9. Kikugawa, K., and M. Beppu, Involvement of lipid oxidation products in the formation of fluorescent and cross-linked proteins, Chem. Phys. Lipids 44: 277297 (1987). 
10. Pearson, A., J. Love, and F. Shorland, Warmed-over flavor in meat, poultry and fish, Adv. Food Res. 23: 2-61 (1977).

11. Frankel, E., Volatile lipid oxidation products, Prog. Lip. Res. 22: 1-33 (1982).

12. Nielsen, H., P. Finot, and R. Hurrell, Reactions of proteins with oxidizing lipids. 1. Analytical measurements of lipid oxidation and of amino acid losses in a whey protein-methyl linolenate model system, British J. Nutrit. 53: 75-86 (1985).

13. Melton, S., Methodology for following lipid oxidation in muscle foods, Food Technol. 37: 105-111, 116 (1983).

14. Kim, R., and F. Labella, Comparison of analytical methods for monitoring autoxidation profiles of authentic lipids, J. Lipid Res. 28: 1110-1117 (1987).

15. Navarro, P., Nutritional value of fish. I. Raw fish, Rev. Agroq. Tecnol. Alim. 31: 330-342 (1991).

16. Tappel, A., Measurement of and protection from in vivo lipid peroxidation, in Free radicals in Biology, edited by W. Pryor, Academic Press, New York, 1980, vol. 4, pp. 1-47.

17. Kikugawa, K., Fluorescent products derived from the reaction of primary amines and compounds in peroxidised lipids, Adv. Free Rad. Biol. Med. 2: 389-417 (1986).

18. Miquel, J., J. Oró, K. Bensch, and J. Johnson, Lipofuscin: Fine-structural and biochemical studies, in Free radicals in Biology, edited by W. Pryor, Academic Press, New York, 1978, vol. 1, pp. 133-182.

19. González-Garza, M., I. Montalvo, and A. Sotelo, Water soluble fluorescent compounds in rat tissue fed cottonseed flour supplemented with vitamin E, $J$. Agric. Food Chem. 38: 340-342 (1990). 
20. Strasburg, G., and R. Ludescher, Theory and applications of fluorescence spectroscopy in food research, Trends Food Sci. Technol. 6: 69-75 (1995).

21. Nair, V., D. Vietti, and C. Cooper, Degenerative chemistry of malondialdehyde. Structure, stereochemistry and kinetics of formation of enaminals from reaction with amino acids, J. Amer. Chem Soc. 103: 3030-3036 (1981).

22. Nair, V., C. Cooper, D. Vietti, and G. Turner, The chemistry of lipid peroxidation metabolites: Crosslinking reactions of malonaldehyde, Lipids 21: 6-10 (1986).

23. Tsuchida, M., T. Miura, K. Mizutani, and K. Aibara, Fluorescent substance in mouse and human sera as a parameter of in vivo lipid peroxidation, Bioch. Bioph. Acta 834: 196-204 (1985).

24. Esterbauer, H., E. Koller, R. Slee, and F. Koster, Possible involvement of the lipid peroxidation product 4-hydroxynonenal in the formation of fluorescent chromolipids, Bioch. J. 239: 405-409 (1986).

25. Montfoort, A., K. Bezstarosti, M. Groh, and J. Koster, The influence of the chain length of aldehydes on the fluorescence of chromolipids, FEBS Letters 226: 101104 (1987).

26. Purdy, R., and A. Tappel, Permeation chromatography of fluorescent products from tissues and peroxidized lipids, J. Chrom. 170: 217-220 (1979).

27. Nielsen, H., Methods for study of protein changes caused by protein-autoxidized lipid interactions, in Chemical changes during food processing, edited by S. Bermell, Instituto de Agroquímica y Tecnología de los Alimentos, Valencia (Spain), 1984, vol II, pp. 54-63.

28. Itälä, L., K. Seppä, U. Turpeinen, and P. Sillanaukee, Separation of hemoglobin acetaldehyde adducts by HPLC-cationexchange chromatography, Anal. Biochem. 224: 323-329 (1995). 
29. Deyl, Z., I. Miksik, and R. Struzinsky, Separation and partial characterizaton of Maillard reaction products by capillary zone electrophoresis, J. Chrom. 516: 287-298 (1990).

30. Tomlinson, A., J. Mlotkiewicz, and I. Lewis, Application of capillary electrophoresis to the separation of coloured products of Maillard reactions, Food Chem. 49: 219-223 (1994).

31. Weist, J., and M. Karel, Development of a fluorescence sensor to monitor lipid oxidation. 1. Fluorescence spectra of chitosan powder and polyamide powder after exposure to volatile lipid oxidation products, J. Agric. Food Chem. 40: 1158-1162 (1992).

32. Bouzas, J., A. Kamarei, and M. Karel, Effect of extraction procedures on fluorescent chromophores in milk, J. Food Sci., 50: 1515-1516 (1985).

33. Maruf, F., D. Ledward, R. Neale, and R. Poulter, Chemical and nutritional quality of Indonesian dried-salted mackerel (Rastrelliger kanagurta), Int. J. Food Sci. Technol. 25: 66-77 (1990).

34. Manwaring, J., and S. Csallani, Water-soluble fluorescent compounds in liver, lung, spleen, kidney, heart and brain of Vitamin E deficient and supplemented mice, $J$. Nutr. 111: 2172-2179 (1981).

35. Pikul, J., D. Leszczynski, A. Niewiarowicz, and F. Kummerow, Lipid oxidation in chicken breast and leg meat after sequential treatments of frozen storage, cooking, refrigerated storage and reheating, J. Food Technol. 19: 575-584 (1984).

36. Smith, G., M. Hole, and S. Hanson, Assessment of lipid oxidation in Indonesian salted-dried Marine catfish (Arius thalassinus), J. Sci. Food Agric. 51: 193-205 (1990). 
37. Hasegawa, K., Y. Endo, and K. Fujimoto, Oxidative deterioration in dried fish model systems assessed by solid sample fluorescence spectrometry, J. Food Sci. 57: 1123-1126 (1992).

38. Fletcher, B., C. Dillard, and A. Tappel, Measurement of fluorescent lipid peroxidation products in biological systems and tissues, Anal. Biochem. 52: 1-9 (1973).

39. Shimasaki, H., N. Ueta, H. Mowri, and K. Inove, Formation of age pigment-like fluorescent substances during peroxidation of lipids in model membranes. Bioch. Bioph. Acta 792: 229-233 (1984).

40. Iio, T., and K. Yoden, Fluorescence formation from hydroperoxide of phosphatidylcholine with amino compound, Lipids 23: 65-67 (1988).

41. Miyagawa, K., K. Hirai, and R. Takeoze, Tocopherol and fluorescence levels in deep-frying oil and their measurement for oil assessment, J. Am. Oil Chem. Soc. 68: 163-166 (1991).

42. Genot, C., T. Montenay-Garestier, and R. Drapron, Intrinsic spectrofluorometry applied to soft wheat (Triticum aestivum) flour and gluten to study lipid-protein interactions, Lebensm.- Wiss. U. Technol. 17: 129-133 (1984).

43. Stapelfeldt, H., H. Bjørn, M. Skovgaard, L. Skibsted, and G. Bertelsen, Warmedover flavor in cooked sliced beef, Z. Lebensm. Unters. Forsch. 195: 203-208 (1992).

44. Hasegawa, K., Y. Endo, and K. Fujimoto, Assessment of lipid oxidation in freezedried pork and egg yolk by solid sample spectrofluorometry, Nippon Shokuhin Kogyo Gakkaishi 40: 150-153 (1993). 
45. Novales, B., D. Bertrand, M. Devaux, P. Robert, and A. Sire, Multispectral fluorescence imaging for the identification of food products, J. Sci. Food Agric. 71: 376-382 (1996).

46. Seiden, P., R. Bro, L. Poll, and L. Munck, Exploring fluorescence spectra of apple juice and their connection to quality parameters by chemometrics, J. Agric. Food Chem. 44: 3202-3205 (1996).

47. Nicoletti, G., Fluorescence of olive oils, Riv. Ital Sost Grasse 67: 389-396 (1990).

48. Wolfbeis, O., and M. Leiner, Characterization of edible oils by fluorescence topography, Mikrochim. Acta I/3-4: 221-233 (1984).

49. Davies, H., Fluorescence of fish muscle: Description and measurement of changes occurring during frozen storage, J. Sci. Food Agric. 33: 1135-1142 (1982).

50. Davies H., and P. Reece, Fluorescence of fish muscle: causes of change occurring during frozen storage, J. Sci. Food Agric. 33: 1143-1151 (1982).

51. Cho, S.-Y., Y. Endo, K. Fujimoto, and T. Kaneda, Autoxidation of ethyl eicosapentaenoate in a defatted fish dry model system, Bull. Jap. Soc. Scient. Fish. 55: 545-552 (1989).

52. Lubis, Z., and A. Buckle, Rancidity and lipid oxidation of dried-salted sardines, Int. J. Food Sci. Technol. 25: 295-303 (1990).

53. Aubourg, S., R. Pérez-Martín, I. Medina, and J. Gallardo, Fluorescence formation by interaction of albacore (Thunnus alalunga) muscle with acetaldehyde in a model system, J. Agric. Food Chem. 40: 1805-1808 (1992).

54. Aubourg, S., R. Pérez-Martín, I. Medina, and J. Gallardo, Fluorescence formation during albacore (Thunnus alalunga) thermal processing, Z. Lebensm. Unters. Forsch. 195: 332-335 (1992). 
55. Aubourg, S., C. Sotelo, and R. Pérez-Martín, Assessment of quality changes in frozen sardine (Sardina pilchardus) by fluorescence detection, J. Amer. Oil Chem. Soc. 75: 575-580 (1998).

56. Quaranta, H., and S. Pérez, Chemical methods for measuring changes in freeze stored fish: A review, Food Chemistry 11: 79-85 (1983).

57. de Koning, A., and T. Mol, Quantitative quality tests for frozen fish: soluble protein and free fatty acid content as quality criteria for hake (Merluccius merluccius) stored at $-18^{\circ} \mathrm{C}$, J. Sci. Food Agric. 54: 449-458 (1991).

58. Miyashita, K., and T. Takagi, Study on the oxidative rate and prooxidant activity of free fatty acids, J. Am. Oil Chem. Soc. 63: 1380-1384 (1986).

59. Han, T.-J., and J. Liston, Correlation between lipid peroxidation and phospholipid hydrolysis in frozen fish muscle, J. Food Sci. 53: 1917-1918 (1988).

60. Bennour, M., A. El Marrakchi, N. Bouchriti, A. Hamama, and M. El Ouadaa, Chemical and microbiological assessments of mackerel (Scomber scombrus) stored in ice, J. Food Protect. 54: 784, 789-792 (1991).

61. Hwang, K., and J. Regenstein, Characteristics of mackerel mince lipid hydrolysis. $J$. Food Sci. 58: 79-83 (1993).

62. Aubourg, S., C. Sotelo, and J. Gallardo, Quality assessment of sardines during storage by measurement of fluorescent compounds, J. Food Sci. 62: 295-298 (1997).

63. Aubourg, S., I. Medina, and J. Gallardo, Quality assessment of blue whiting (Micromesistius poutassou) during chilled storage by monitoring lipid damages, J. Agric. Food Chem. 46: 3662-3666 (1998). 
64. Aubourg, S., I. Medina, and R. Pérez-Martín, A comparison between conventional and fluorescence detection methods of cooking-induced damage to tuna fish lipids, Z. Lebensm. Unters. Forsch. 200: 252-255 (1995).

65. Aubourg, S., and I. Medina, Quality differences assessment in canned sardine (Sardina pilchardus) by fluorescence detection, J. Agric. Food Chem. 45: 36173621 (1997).

66. Aubourg, S., and J. Gallardo, Fluorescence changes in amine model systems related to fish deterioration, Int. J. Food Sci. Technol. 32: 153-158 (1997).

67. Aubourg, S., Fluorescence detection in aldehyde containing model systems: Relationship with fish deterioration, Grasas y Aceites (1997), in press.

68. Shenouda, S., Theories of protein denaturation during frozen storage of fish flesh, Adv. Food Res. 26: 275-311 (1980).

69. Sotelo, C., C. Piñeiro, and R. Pérez-Martín, Review: Denaturation of fish proteins during frozen storage: Role of formaldehyde, Z. Lebensm. Unters. Forsch. 200: 14-23 (1995).

70. Aubourg, S., Influence of formaldehyde in the formation of fluorescence related to fish deterioration, Z. Lebensm. Unters. Forsch. 206: 29-32 (1998).

71. Aubourg, S., Effect of $\mathrm{pH}$ on fluorescence formation related to fish deterioration, $Z$. Lebensm. Unters. Forsch. 207: 268-272 (1998).

72. Lehninger, A., Los aminoácidos, sillares de las proteínas, in Bioquímica, Editorial Omega S. A., Barcelona (Spain), 1979, pp. 80-82. 


\section{FIGURES LEGENDS}

Figure 1: Formation of covalent interaction structures starting from primary amines and lipid oxidation compounds.

Figure 2: Principal component analysis for different parameters measured during sardine frozen storage at $-18^{\circ} \mathrm{C}$. Abbreviations: ST (storage time), TVB-N (total volatile base-nitrogen), CD (conjugate dienes), TBA-i (thiobarbituric acid index), FFA (free fatty acids), $\delta \mathbf{F}_{\mathbf{a q}}$ and $\delta \mathbf{F}_{\text {or }}$ (fluorescence ratios measured in the aqueous and organic phases, respectively). Adapted from Reference 55.

Figure 3: Principal component analysis for different parameters measured during sardine frozen storage at $-10^{\circ} \mathrm{C}$ storage. Abbreviations as specified in Figure 2. Adapted from Reference 55.

Figure 4: Nonlinear relationship between $\delta F_{\text {aq }}$ and Time of refrigerated storage. Adapted from Reference 63.

Figure 5: Linear relationship between $\delta \mathbf{F}_{\mathrm{aq}}$ and TVB-N. Adapted from Reference 63. 
TABLE 1: Correlation coefficient matrix for different parameters ${ }^{a}$ measured during refrigerated storage of sardines $\left(0^{\circ} \mathrm{C}\right.$, on ice: Table $\left.\mathbf{1 A}\right)$ and at $15^{\circ} \mathrm{C}(\text { Table } \mathbf{1 B})^{b}$

Table 1A

\begin{tabular}{|c|c|c|c|c|c|}
\hline & TVB-N & $\mathrm{CD}$ & TBA-i & FFA & $\delta \mathrm{F}_{\mathrm{aq}}$ \\
\hline $\mathrm{ST}$ & $0.86^{c}$ & 0.04 & 0.50 & 0.50 & $0.94^{C}$ \\
\hline TVB-N & & -0.11 & 0.06 & 0.31 & $0.93^{C}$ \\
\hline $\mathrm{CD}$ & & & 0.48 & $0.57^{c}$ & -0.03 \\
\hline TBA-i & & & & $0.78^{c}$ & 0.28 \\
\hline FFA & & & & & 0.42 \\
\hline
\end{tabular}

$\underline{\text { Table 1B }}$

\begin{tabular}{|c|c|c|c|c|c|}
\hline & TVB-N & CD & TBA-i & FFA & $\delta \mathrm{F}_{\mathrm{aq}}$ \\
\hline ST & $0.99^{c}$ & $0.85^{c}$ & $0.58^{c}$ & $0.93^{c}$ & $0.93^{c}$ \\
\hline TVB-N & & $0.84^{c}$ & 0.51 & $0.93^{c}$ & $0.92^{c}$ \\
\hline CD & & & $0.61^{c}$ & $0.84^{c}$ & $0.90^{c}$ \\
\hline TBA-i & & & & $0.61^{c}$ & $0.59^{c}$ \\
\hline FFA & & & & & $0.92^{c}$ \\
\hline
\end{tabular}

a Abbreviations: ST (storage time), TVB-N (total volatile base-nitrogen), CD (conjugated dienes), TBA-i (thiobarbituric acid index), FFA (free fatty acids) and $\delta \mathbf{F}_{\mathbf{a q}}$ (fluorescence shift ratio measured in the aqueous phase resulting after the lipid extraction).

${ }^{b}$ Adapted from Reference 62.

${ }^{c}$ Significance: $\mathrm{p}<0.05$.

TABLE 2: Lipid damage indices ${ }^{a}$ expressed as the cooked/raw measurements ratio in the different samples studied ${ }^{b, c}$ 


\begin{tabular}{|c|c|c|c|c|c|}
\hline Sample & FFA & $\mathrm{CD}$ & Carbonyls & Browning & $\delta F_{\text {or }}$ \\
\hline BE1 & 2.10 & 0.63 & 3.17 & 1.60 & 1.56 \\
\hline BE2 & 1.76 & 0.67 & 2.96 & 2.85 & 1.55 \\
\hline BE3 & 1.27 & 0.39 & 2.08 & 1.13 & 1.32 \\
\hline BE4 & 1.77 & 0.47 & 3.94 & 1.81 & 1.27 \\
\hline BE5 & 2.24 & 0.57 & 3.56 & 1.83 & 1.63 \\
\hline BF1 & 1.36 & 0.89 & 3.65 & 2.88 & 1.59 \\
\hline BF2 & 2.36 & 2.36 & 4.03 & 4.17 & 1.68 \\
\hline BF3 & 3.44 & 1.03 & 3.73 & 4.45 & 1.60 \\
\hline BF4 & 2.26 & 2.42 & 2.27 & 2.34 & 1.26 \\
\hline Mean & 2.06 & 1.05 & 3.27 & 2.56 & 1.50 \\
\hline SD & 0.61 & 0.74 & 0.67 & 1.08 & 0.15 \\
\hline VC & 29.47 & 70.48 & 20.49 & 42.19 & 10.00 \\
\hline
\end{tabular}

${ }^{a}$ Abbreviations employed: $\delta \mathbf{F}_{\text {or }}$ (fluorescence shift ratio measured in the lipid extract), SD (standard deviation) and VC (variation coefficient). Remaining abbreviations as specified in Table 1 .

${ }^{b}$ BE1-BE5: five individual fish samples of big eye tuna (Thunnus obesus); BF1-BF4: four individual fish samples of bluefin tuna (Thunnus thynnus).

${ }^{c}$ Adapted from Reference 64. 
TABLE 3: Lipid damage measurements ${ }^{1}$ in brine canned sardine (BCS) $)^{2,3,4}$

\begin{tabular}{|c|c|c|c|c|c|c|}
\hline Sample & FFA & TBA-i & PI & $\delta F_{a q}$ & $\delta F_{\text {or }}$ & $\delta \mathrm{F}_{\mathrm{pm}}$ \\
\hline IN-CH & $0.20 \mathrm{a}$ & $0.98 \mathrm{a}$ & $1.66 \mathrm{a}$ & $0.78 \mathrm{a}$ & $1.50 \mathrm{a}$ & - \\
\hline BCS-0 & $4.11 \mathrm{~b}$ & $2.10 \mathrm{c}$ & $1.72 \mathrm{a}$ & 2.22 bc & $2.71 \mathrm{ab}$ & $1.75 \mathrm{a}$ \\
\hline BCS-2 & $3.98 \mathrm{~b}$ & 1.89 bc & $1.65 \mathrm{a}$ & $2.36 \mathrm{bc}$ & $2.87 \mathrm{ab}$ & $1.73 \mathrm{a}$ \\
\hline BCS-6 & 4.35 bc & 1.73 bc & $1.62 \mathrm{a}$ & 2.52 bc & $6.99 \mathrm{abc}$ & $2.22 \mathrm{ab}$ \\
\hline BCS-10 & $4.68 \mathrm{bc}$ & 1.81 bc & $1.65 \mathrm{a}$ & 2.22 bc & 9.00 bc & $3.35 \mathrm{~b}$ \\
\hline BCS-13 & $5.84 \mathrm{~cd}$ & 2.02 c & $1.58 \mathrm{a}$ & $2.04 \mathrm{~b}$ & 12.22 c & $5.08 \mathrm{c}$ \\
\hline BCS-15 & $6.93 \mathrm{~d}$ & $1.49 \mathrm{ab}$ & $1.59 \mathrm{a}$ & $2.78 \mathrm{c}$ & $10.93 \mathrm{c}$ & $6.92 \mathrm{~d}$ \\
\hline
\end{tabular}

1 Measurements abbreviations: PI (polyene index) and $\delta \mathbf{F}_{\mathbf{p m}}$ (fluorescence shift measured in the packing medium). Remaining abbreviations as specified in Tables 1 and 2.

${ }^{2}$ Sample names: IN-CH (initial raw sardine); BCS-0, BCS-2, BCS-6, BCS-10, BCS-13 and BCS-15 (canned sardine that was previously kept refrigerated at $0^{\circ} \mathrm{C}$ on ice during $0,2,6,10,13$ and 15 days, respectively).

${ }^{3}$ Mean values of three determinations. Values in the same column followed by different letters are significantly different $(\mathrm{p}<0.05)$.

${ }^{4}$ Adapted from Reference 65. 
TABLE 4: Lipid damage measurements ${ }^{1}$ in oil canned sardine (OCS) $)^{2,3,4}$

\begin{tabular}{|c|c|c|c|c|c|}
\hline Sample & FFA & TBA-i & $\delta \mathrm{F}_{\mathrm{aq}}$ & $\delta F_{\text {or }}$ & $\delta \mathrm{F}_{\mathrm{pm}}$ \\
\hline IN-FR & $1.11 \mathrm{a}$ & $0.48 \mathrm{a}$ & $0.37 \mathrm{a}$ & $0.43 \mathrm{a}$ & - \\
\hline OCS-0 & $0.62 \mathrm{a}$ & $1.53 \mathrm{c}$ & $1.74 \mathrm{ab}$ & $3.53 \mathrm{~b}$ & $0.93 \mathrm{a}$ \\
\hline OCS-0.5 & $3.17 \mathrm{~b}$ & $1.77 \mathrm{~cd}$ & 3.75 c & $4.65 \mathrm{bc}$ & $1.20 \mathrm{a}$ \\
\hline OCS-2 & $4.75 \mathrm{c}$ & $1.13 \mathrm{~b}$ & $5.98 \mathrm{~d}$ & $4.13 \mathrm{bc}$ & $1.21 \mathrm{a}$ \\
\hline OCS-4 & $3.16 \mathrm{~b}$ & $1.11 \mathrm{~b}$ & $2.62 \mathrm{bc}$ & 4.99 с & $1.88 \mathrm{~b}$ \\
\hline OCS-8 & $2.83 \mathrm{~b}$ & $1.96 \mathrm{~d}$ & 3.48 с & $8.08 \mathrm{~d}$ & $2.25 \mathrm{~b}$ \\
\hline OCS-12 & $4.81 \mathrm{C}$ & $1.39 \mathrm{bc}$ & $7.51 \mathrm{~d}$ & $6.85 \mathrm{~d}$ & $4.56 \mathrm{c}$ \\
\hline
\end{tabular}

${ }^{1}$ Measurements abbreviations as specified in Table 3.

2 Sample names: IN-FR (initial raw sardine), OCS-0, OCS-0.5, OCS-2, OCS-4, OCS8 and OCS-12 (canned sardine that was previously kept frozen at $-18^{\circ} \mathrm{C}$ during $0,0.5,2,4,8$ and 12 months, respectively).

${ }^{3}$ Mean values of three determinations. Values in the same column followed by different letters are significantly different $(\mathrm{p}<0.05)$.

${ }^{4}$ Adapted from Reference 65. 
TABLE 5: Fluorescence ratio $(\delta \mathrm{F})$ values ${ }^{1}$ obtained by reaction at $30{ }^{\circ} \mathrm{C}$ of cod liver oil and primary amines with different chain lengths ${ }^{2,3}$

\begin{tabular}{|c|c|c|c|}
\hline & 1 day & 7 days & 25 days \\
\hline CLO & $2.30 \mathrm{a}$ & $2.26 \mathrm{a}$ & $2.37 \mathrm{a}$ \\
\hline CLO + MA & $6.16 \mathrm{c}$ & 17.6 cd & 29.5 b \\
\hline CLO + EA & $5.09 \mathrm{~b}$ & $14.5 \mathrm{~b}$ & $31.5 \mathrm{~b}$ \\
\hline CLO + PA & 5.35 bc & 16.2 bc & 35.1 c \\
\hline $\mathrm{CLO}+\mathrm{BA}$ & 5.85 с & $17.2 \mathrm{~cd}$ & 37.6 c \\
\hline $\mathrm{CLO}+\mathrm{OA}$ & 5.70 с & $19.7 \mathrm{~d}$ & $44.9 \mathrm{~d}$ \\
\hline
\end{tabular}

${ }^{1}$ Values in the same column followed by different letters are significantly different $(\mathrm{p}<$ $0.05)$.

2 Abbreviations: CLO (cod liver oil), MA (methylamine), EA (ethylamine), PA (propylamine), BA (butylamine), OA (octylamine).

${ }^{3}$ Adapted from Reference 66. 
TABLE 6: Fluorescence ratio $(\delta \mathrm{F})$ values ${ }^{1}$ obtained from the aqueous medium of the aldehyde-fish muscle reaction systems at $30^{\circ} \mathrm{C}^{2,3}$

\begin{tabular}{|c|c|c|c|}
\hline & 1 day & 7 days & 25 days \\
\hline MCM & $0.88 \mathrm{ab}$ & $0.97 \mathrm{a}$ & 1.18 a \\
\hline $\mathrm{FA}+\mathrm{MCM}$ & $1.18 \mathrm{~b}$ & 1.18 a & $1.53 \mathrm{a}$ \\
\hline $\mathrm{Pal}+\mathrm{MCM}$ & $6.03 \mathrm{~d}$ & $22.6 \mathrm{~d}$ & $37.1 \mathrm{~d}$ \\
\hline $\mathrm{Hal}+\mathrm{MCM}$ & $3.23 \mathrm{c}$ & 18.2 с & $26.8 \mathrm{c}$ \\
\hline MSM & 0.53 a & 0.65 a & $1.21 \mathrm{a}$ \\
\hline $\mathrm{FA}+\mathrm{MSM}$ & $1.48 \mathrm{~b}$ & $3.46 \mathrm{~b}$ & $6.73 \mathrm{~b}$ \\
\hline
\end{tabular}

${ }^{1}$ Values in the same column followed by different letters are significantly different $(\mathrm{p}<$ $0.05)$.

2 Abbreviations: MCM (minced cod muscle), MSM (minced sardine muscle), FA (formaldehyde), Pal (propanal) and Hal (hexanal).

${ }^{3}$ Adapted from Reference 70. 
TABLE 7: Fluorescence ratio $(\delta \mathrm{F})$ values ${ }^{1}$ obtained from the aqueous medium of the reaction systems with formaldehyde and minced hake at different $\mathrm{pH}$ at $30^{\circ} \mathrm{C}^{2}$.

Reaction pH value

time (days)

\begin{tabular}{|c|c|c|c|c|}
\hline & 5.0 & 6.0 & 7.0 & 8.0 \\
\hline 1 & $0.80 \mathrm{a}$ & $0.96 \mathrm{a}$ & $1.88 \mathrm{c}$ & $1.59 \mathrm{~b}$ \\
\hline 2 & $1.00 \mathrm{a}$ & $1.30 \mathrm{a}$ & $2.68 \mathrm{~b}$ & $2.43 \mathrm{~b}$ \\
\hline 4 & $1.36 \mathrm{a}$ & $1.51 \mathrm{a}$ & 7.38 с & $5.36 \mathrm{~b}$ \\
\hline 7 & 1.78 a & $2.46 \mathrm{a}$ & $9.08 \mathrm{~b}$ & $9.79 \mathrm{~b}$ \\
\hline 15 & $2.94 \mathrm{a}$ & $3.51 \mathrm{a}$ & $16.41 \mathrm{~b}$ & $17.94 \mathrm{~b}$ \\
\hline 30 & $4.98 \mathrm{a}$ & $6.57 \mathrm{a}$ & $42.49 \mathrm{~b}$ & 63.79 с \\
\hline
\end{tabular}

${ }^{1}$ Mean values of three independent determinations. Values in the same row followed by different letters (a, b, c) are significantly different $(\mathrm{p}<0.05)$.

${ }^{2}$ Adapted from Reference 71. 
Reaction 1:

$\mathrm{R}-\mathrm{CHR}$ - $\mathrm{OOH}+\mathrm{R}$ ' $-\mathrm{NH}_{2} \longrightarrow \mathrm{R}-\mathrm{OH}+\mathrm{R}$ - $\mathrm{CH}=\mathrm{N}-\mathrm{R}$ '”

(lipid peroxide) (primary amine) (Schiff base)

Reaction 2:

$\mathrm{R}-\mathrm{CHO}+\mathrm{R}^{\prime}-\mathrm{NH}_{2} \longrightarrow \mathrm{R}-\mathrm{CHOH}-\mathrm{NHR}{ }^{\prime} \longrightarrow \mathrm{R}-\mathrm{CH}=\mathrm{N}-\mathrm{R}^{\prime}$

(aldehyde) (primary amine) (Schiff base)

Reaction 3:

$\mathrm{R}-\mathrm{CH}_{2}-\mathrm{CH}=\mathrm{N}-\mathrm{R}$ ' + R' $-\mathrm{CHO}$

(Schiff base)

(aldehyde)
$\mathrm{R}-\mathrm{C}=\mathrm{CH}-\mathrm{R}$,
$\mathrm{CH}=\mathrm{N}-\mathrm{R}$,
(conjugated Schiff base)


TABLE 0: Correlation coefficients matrix for different parameters ${ }^{a}$ measured during frozen storage of sardine $\left(-18^{\circ} \mathrm{C} \text { : Table } 1 \mathrm{~A} ;-10^{\circ} \mathrm{C} \text { : Table } 1 \mathbf{B}\right)^{b}$.

Table 0A

\begin{tabular}{|c|c|c|c|c|c|}
\hline & TVB-N & $\mathrm{CD}$ & TBA-i & FFA & $\delta \mathrm{F}$ \\
\hline ST & $0.52^{c}$ & 0.09 & $0.79^{d}$ & $0.82^{d}$ & $0.80^{d}$ \\
\hline TVB-N & & $0.43^{c}$ & 0.36 & $0.46^{c}$ & 0.34 \\
\hline CD & & & -0.22 & -0.10 & -0.15 \\
\hline TBA-i & & & & $0.87^{d}$ & $0.92^{d}$ \\
\hline FFA & & & & & $0.83^{d}$ \\
\hline
\end{tabular}

Table 0B

\begin{tabular}{|c|c|c|c|c|c|}
\hline & TVB-N & $\mathrm{CD}$ & TBA-i & FFA & $\delta \mathrm{F}$ \\
\hline ST & $0.55^{c}$ & -0.07 & $0.94^{d}$ & $0.88^{d}$ & $0.72^{c}$ \\
\hline TVB-N & & 0.07 & 0.61 & $0.71^{c}$ & $0.60^{c}$ \\
\hline CD & & & 0.14 & -0.03 & 0.27 \\
\hline TBA-i & & & & $0.84^{d}$ & $0.81^{\circ}$ \\
\hline FFA & & & & & $0.59^{c}$ \\
\hline
\end{tabular}

a Abbreviations: ST (storage time), TVB-N (total volatile base-nitrogen), CD (conjugated dienes), TBA-i (thiobarbituric acid index), FFA (free fatty acids) and $\delta \mathrm{F}$ (fluorescence shift ratio measured in the aqueous phase resulting after the lipid extraction).

${ }^{b}$ Adapted from Reference 45.

${ }^{c}$ Significance: $\mathrm{p}<0.05$.

${ }^{d}$ Significance: $\mathrm{p}<0.01$. 